Research Article

\title{
TLR7 Polymorphism (rs179008 and rs179009) in HIV-Infected Individual Naïve to ART
}

\author{
HariOm Singh $\mathbb{D}^{1},{ }^{1}$ Dharmesh Samani, ${ }^{1}$ and Sumit Aggarwal ${ }^{2}$ \\ ${ }^{1}$ Department of Molecular Biology, National AIDS Research Institute Pune, 411026, India \\ ${ }^{2}$ Division of ECD, Indian Council of Medical Research-HQ, New Delhi 110029, India \\ Correspondence should be addressed to HariOm Singh; hariomsgpgims@gmail.com
}

Received 19 February 2020; Accepted 21 April 2020; Published 20 May 2020

Academic Editor: Mirella Giovarelli

Copyright (C) 2020 HariOm Singh et al. This is an open access article distributed under the Creative Commons Attribution License, which permits unrestricted use, distribution, and reproduction in any medium, provided the original work is properly cited.

Toll-like receptors (TLRs) play an important role in the innate immune response to HIV infection. Single nucleotide polymorphism (SNP) in TLR7 (Gln11Leu) gene has been associated with a rapid decline of CD4T cell count. Hence, we assessed the TLR7 (rs179008, Gln11Leu (A/T) and rs179009, IVS2-151 (A/G)) polymorphism in $150 \mathrm{HIV-infected} \mathrm{individuals} \mathrm{naïve} \mathrm{to} \mathrm{ART}$ and 158 healthy controls. The genotyping of TLR7 Gln11Leu (A/T) and IVS2-151 (A/G) polymorphisms was done using the PCR-RFLP method. In univariate analysis, none of the genotype and haplotype of TLR7 Gln11Leu (A/T) and IVS2-151 (A/G) polymorphism differed significantly between HIV-infected individuals and healthy controls. The occurrence of TLR7 rs179009AG genotype in the codominant model and rs179009 AG-GG genotype in the dominant model was significantly reduced in HIV-infected individuals as compared to healthy controls $(18.0 \%$ vs. $29.1 \%, \mathrm{OR}=0.42, P=0.016 ; 26.7 \%$ vs. $36.7 \%, \mathrm{OR}=0.52, P=0.016)$. TLR7 rs179009AG genotype was significantly underrepresented in the intermediate HIV disease stage compared with healthy controls $(\mathrm{OR}=0.03, P=0.04)$. TLR7 rs179009AG genotype expressed higher in tobaccoconsuming HIV-infected individuals compared with nonusers ( $\mathrm{OR}=1.71, P=0.47)$. In conclusion, rs179009 AG-GG and AG genotypes were found reduced in HIV-infected individuals as compared to healthy controls; their higher prevalence in health individuals clearly support that they are associated with reduced risk of acquisition of HIV-1 infection.

\section{Introduction}

In India, HIV remains to be one of the major issues (WHO, HIV/AIDS Fact sheet November 2017). The difference in susceptibility to the acquisition of HIV and disease progression is associated with a genetic background [1]. Innate immunity is known to play a crucial role in response to viral pathogens [2]. Toll-like receptors (TLRs) are pathogen recognition receptors (PRRs) that play a pivotal role in the innate immune system and control inflammatory responses and adaptive immunity [3]. PRRs recognize evolutionarily conserved pathogen-associated molecular patterns (PAMPs), and PAMP recognition triggers activation of signal transduction pathways and downstream effector responses [4, 5]. TLR families like TLR1, TLR2, TLR4, and TLR6 are localized on the cell surface and TLR3, TLR7, TLR8, and TLR9 are localized in endosomal membranes inside the cell $[4,5]$.
TLR7 plays an important role in an antiviral immune response. TLR7 recognizes RNA of various viruses including HIV [6]. TLR7 bind single-stranded RNA [7]. It shares a high degree of structural similarity, and their activation leads to nuclear factor-kappa B (NF- $\kappa$ B) activation and subsequent production of inflammatory cytokines [8]. The TLR7 gene span $16 \mathrm{~kb}$ apart, located on the Xp22.2 chromosome [9]. Single nucleotide polymorphisms (SNPs) in TLR genes may contribute to differences in the acquisition of HIV-1 and disease progression [6]. Some of the studies reported that the functional polymorphism of TLR7 rs179008, Gln11Leu was associated with HIV acquisition [10], higher viral loads and accelerated progression to advanced immune suppression in HIV patients [6], hepatitis C infection [11], basal cell carcinoma (BCC) [12], female HCV patients, and spontaneous clearance of HCV [13]. Elefanti et al., [14] have been reported that TLR7 32A/T polymorphism was not associated with melanoma cases. Similarly, TLR7 rs179009, IVS2-151A/G 
polymorphism was associated with spontaneous clearance of HCV in female patients [13] and chronic hepatitis C [15]. Wang et al., [16] reported the frequency of IVS2-151A allele (77\%) was higher as compared to IVS2-151G (22\%). TLR7 $32 \mathrm{~A} / \mathrm{T}$ polymorphism was associated with $\mathrm{HIV}-1$ disease progression in HIV-1-infected women compared to uninfected women [6]. TLR7 rs5743737 and TLR7 rs1634323 polymorphisms were associated with a decreased risk of $\mathrm{BV}$ while TLR7 rs179012 was associated with an increased risk [17].

Till now, none of the studies reported the association of TLR7 polymorphisms (rs179008 and rs179009) with the $\mathrm{HIV}$ infection and disease progression from India. Hence, we attempted to assess the distribution of TLR7 polymorphisms (rs179008 and rs179009) in HIV-infected individuals naïe to ART from the Western Indian population.

\section{Materials and Methods}

2.1. Subjects. The subject recruitment period was April 2014 to March 2017; $153 \mathrm{HIV}$-infected individuals naive to ART, aged between 18 and 50 years, were consecutively taken from the outdoor patient clinics of the National AIDS Research Institute, Pune. At the same time, 158 individuals free of (individuals from the same family excluded) HIV, hepatitis $\mathrm{B}$ and $\mathrm{C}$, and tuberculosis were age-matched and serum negative from ELISA tests were recruited from the clinic belonging to the same institution. Clinical data was collected via a questionnaire, personal interviews, and review of case records. The estimation of CD4 count was done by fluorescenceactivated cell sorting (FACS). CD4+ count $<350$ cells $/ \mathrm{mm}^{3}$, $350-500$ cells $/ \mathrm{mm}^{3}$, and $>500$ cells $/ \mathrm{mm}^{3}$ were considered as advanced, intermediate, and early stage of HIV infection. ELISA for hepatitis C and HBsAg testing was performed using the Ortho HCV ELISA test system and Murex HBsAg confirmatory (DiaSorin) ELISA. Environmental exposures (tobacco and alcohol consumption) were also recorded in the questionnaire. The study was approved by local ethics committees of the institute, and all participants gave informed signed consent. Two $\mathrm{ml}$ of the peripheral blood sample was collected and stored at $-700^{\circ} \mathrm{C}$ before DNA extraction. Genomic DNA extraction was done from peripheral blood leukocyte pellet using the AxyPrep Blood Genomic DNA Miniprep Kit according to the protocol given by the manufacturer.

2.2. Genotyping. Single nucleotide polymorphisms (rs179008 and rs179009) of the TLR7 gene were genotyped in subjects using polymerase chain reaction-restriction fragment length polymorphism (PCR-RFLP).

The primer for the amplification of TLR7 polymorphisms was used as reported by [18]. The primer sequence of TLR7 rs179008 and rs179009 polymorphisms was F: $5^{\prime}$-TAACAACGAATAGG AAAATGC- $3^{\prime}$ and R: $5^{\prime}$ -GTTTTAGGAAACCATCTAGCC-3' [18]. A total volume of $25 \mu \mathrm{l}$ with $20 \mathrm{pmol}$ of each primer, genomic DNA (100$150 \mathrm{ng}$ ), $10 \mathrm{mM}$ deoxynucleotide triphosphates, PCR buffer containing $100 \mathrm{mM}$ Tris- $\mathrm{HCl}, \mathrm{pH} 8.6,50 \mathrm{mM} \mathrm{KCl}, 1.5 \mathrm{mM}$ $\mathrm{MgCl}_{2}$, and 1.5 units of Taq polymerase (Bangalore Genei,
India) was used for PCR. The reaction conditions for TLR7 polymorphisms (rs179008) were initial denaturation at $94^{\circ} \mathrm{C}$ for $5 \mathrm{~min}$, followed by 35 cycles of denaturation at $94^{\circ} \mathrm{C}$ for $35 \mathrm{sec}$, annealing at $54^{\circ} \mathrm{C}$ for $30 \mathrm{sec}$, extension at $72^{\circ} \mathrm{C}$ for $1 \mathrm{~min}$, and final extension at $72^{\circ} \mathrm{C}$ for $5 \mathrm{~min}$. Amplified products of rs179008 and rs179009 polymorphisms were digested using restriction enzyme ApoI and NlaIII (MBI Fermentas Inc., USA), respectively. Genotyping of TLR7 polymorphisms was done in $15 \%$ polyacrylamide gel using molecular weight markers and visualized after staining with ethidium bromide. Based on sequences and location of SNP, TLR7 polymorphism rs179008 A/T was genotyped as assigned as follows: $166 \mathrm{bp}$ $+37 b p+66 b p$ for AA, $203 b p+166 b p+37 b p+66 b p$ for AT, and $203 \mathrm{bp}+66 \mathrm{bp}$ for TT. TLR7 rs179009 A/G was genotype as $122 b p+247 b p$ for AA, $122 b p+247 b p+369 b p$ for AG, and 369 bp for GG. Veriti 96 well thermal cycler was used for amplification of reactions (Applied Biosystems, USA). PCR products and molecular weight markers were visualized after staining with ethidium bromide. Twenty percent of samples from both patients and controls were regenotyped by other laboratory personnel, and no discrepancy in genotyping was noticed. Sequencing was done in $10 \%$ of samples to assess the genotyping error.

2.3. Data Analysis. The age variable was expressed as a mean \pm standard deviation (SD). The $\chi^{2}$ goodness-of -fit test was used for any deviation from Hardy-Weinberg equilibrium in controls. We used the $\chi^{2}$ statistic (Fisher's exact test for cell size $<5)$ to compare genotype frequency between $\mathrm{HIV}$-infected individuals vs. healthy controls. SNPStats software was used to compare haplotype frequency between $\mathrm{HIV}$-infected individuals and controls. Interaction of tobacco use, alcohol intake, and genotypes was examined in all eligible $\mathrm{HIV}$-infected individuals. Odds ratios (ORs) and $95 \%$ confidence interval (CI) were calculated by unconditional binary logistic regression. All statistical analysis was performed using SPSS software version 17.0 (SPSS, Chicago, IL, USA), and tests of statistical significance were two-sided and taken as significant when $P$ value was less than 0.05 .

\section{Results}

In the present study, we enrolled $150 \mathrm{HIV}$-infected individuals and 158 healthy controls. The mean age (years \pm SD) of HIV-infected individuals and healthy controls were 36 yrs \pm 3.2 and 33 yrs \pm 6.47 , respectively. The demographic profile of HIV-infected individuals and healthy controls is shown in Table 1.

\subsection{Genotype-Phenotype Association}

3.1.1. TLR7 (rs179008 and rs179009) Polymorphism and HIV-Infected Individuals. The occurrence of TLR7 polymorphism in HIV-infected individuals and healthy controls is shown in Table 2. Polymorphisms rs179008 and rs179009 in TLR7 gene followed the Hardy-Weinberg equilibrium $(P=0.07,0.05)$ in healthy controls. The distribution of rs179009 AG genotype in the codominant model, rs179009 
TABLE 1: Characteristics of HIV-infected individuals and healthy controls.

\begin{tabular}{lcc}
\hline Subjects & HIV-infected individuals & Healthy controls \\
\hline Number & 150 & 158 \\
Mean age (range) & $36 \pm 3.2$ & $33 \pm 6.47$ \\
Sex & & (years \pm SD) \\
Females & $76(50.07 \%)$ & $41(25.09 \%)$ \\
Males & $74(49.03 \%)$ & $117(74.01 \%)$ \\
Alcohol habit & $18(11.76 \%)$ & $23(14.74 \%)$ \\
User & $90(58.82 \%)$ & $133(85.25 \%)$ \\
Nonuser & & $22(14.10 \%)$ \\
Tobacco habit & $22(14.37 \%)$ & $134(85.89 \%)$ \\
User & $86(56.20 \%)$ & \\
Nonuser & & NA \\
CD4+ status & $68(44.44 \%)$ & NA \\
$0-350$ & $41(26.79 \%)$ & NA \\
$351-500$ & $44(28.75 \%)$ & \\
501 above &
\end{tabular}

$0=$ data was not recorded in questionnaire form; $\mathrm{NA}=$ not applicable.

AG-GG genotype in the dominant model, and rs179009 AG genotype in the overdominant model was significantly reduced in HIV-infected individuals as compared to healthy controls $(18.0 \%$ vs. $29.1 \%, \mathrm{OR}=0.42,95 \% \mathrm{CI}: 0.23-0.77$, $P=0.016 ; 26.7 \%$ vs. $36.7 \%, \mathrm{OR}=0.52,95 \% \mathrm{CI}: 0.30-0.89$, $P=0.016$, and $18 \%$ vs. $29.1 \%, \mathrm{OR}=0.42,95 \% \mathrm{CI}: 0.23-$ $0.77, P=0.0039)$.

3.1.2. TLR7 Haplotypes in HIV-Infected Individuals. The distribution of TLR7 haplotypes (rs179008 and rs179009) in $\mathrm{HIV}$-infected individuals and healthy controls is shown in Table 3. In both polymorphisms, a nonsignificant association was observed in the linkage disequilibrium (LD) $\left(D^{\prime}\right)$ between HIV-infected individuals vs. healthy controls $\left(D^{\prime}\right.$ : 0.2663$)$. Haplotype AG (rs $\left.179008 * \mathrm{~A} / \mathrm{rs} 179009 * \mathrm{G}\right)$ was found to be higher in $\mathrm{HIV}$-infected individuals as compared to healthy controls $(7.00 \%$ vs. $5.41 \%$, OR = 1.35, 95\% CI: 0.64-2.84, $P=0.43$ ). Haplotypes AA, TA, and TG $(\mathrm{rs} 179008 * \mathrm{~A}, * \mathrm{~T}, * \mathrm{~T} / \mathrm{rs} 179009 * \mathrm{~A}, * \mathrm{~A}, * \mathrm{G})$ were expressed almost similarly $(75.33 \%$ vs. $72.44 \%, 14.33 \%$ vs. $16.8 \%$, and $3.33 \%$ vs. $5.35 \%$ ) (Table 3 ).

3.1.3. TLR7 Polymorphism and HIV Disease Stages. The prevalence of TLR7 rs179009 AG genotype was observed less in early, intermediate, and advanced HIV disease stage individuals as compared to healthy controls (5.0\% vs. $29.1 \%$, $\mathrm{OR}=0.11,95 \% \mathrm{CI}: 0.02-0.52, P=0.001 ; 5.7 \%$ vs. $29.1 \%$, $\mathrm{OR}=0.03,95 \%$ CI: $0.11-0.96, P=0.04 ;$ and $4.7 \%$ vs. $29.1 \%, \quad$ OR $=0.11, \quad 95 \% \quad$ CI: $\quad 0.03-0.39, \quad P \leq 0.001)$. Frequency of TLR7 rs179009 GG genotype was reduced in advanced HIV disease stage as compared with healthy controls $(1.6 \%$ vs. $7.6 \%, \mathrm{OR}=0.14,95 \% \mathrm{CI}$ : $0.01-1.07$, $P=0.03)$ (Table 4).

\subsection{Gene-Environment Interaction}

3.2.1. TLR7 Polymorphism and Environmental Factors. Consumption of tobacco and alcohol in HIV-infected individuals was analyzed for TLR7 polymorphism (Table 5). TLR7 (rs179008 and rs179009) polymorphisms did not differ between HIV-infected individuals with and without tobacco and alcohol users. The distribution of TLR7 rs179009AG genotype was found to be higher in tobacco-consuming $\mathrm{HIV}$-infected individuals as compared to nonusers $(26.1 \%$ vs. $17.2 \%, \mathrm{OR}=1.71,95 \% \mathrm{CI}: 0.52-5.49, P=0.47)$. The prevalence of TLR7 rs179008 CC, CT, and TT genotypes was almost corresponding between tobacco-consuming HIVinfected individuals and nonconsuming ( $82.6 \%$ vs. $82.8 \%$, $13.0 \%$ vs. $13.9 \%$, and $4.3 \%$ vs. $3.3 \%$ ). TLR7 rs179008 AA, AT, and TT and rs179009 AA, AG and GG genotypes distributed almost alike between alcohol taking HIV-infected individuals and nonusers (87.0\% vs. $81.9 \%, 13.0 \%$ vs. $14.2 \%$, and $0.0 \%$ vs. $3.9 \%$ and $78.3 \%$ vs. $72.4 \%, 17.4 \%$ vs. $18.1 \%$, and $4.3 \%$ vs. $9.4 \%)$.

3.2.2. Multivariate Logistic Regression Analysis. Correlation of age, sex, tobacco, alcohol, baseline CD4 counts, and TLR7 (rs179008 and rs179009) polymorphisms with HIV disease progression was done by multivariate logistic regression analysis. TLR7 (rs179008 and rs179009) polymorphisms, age, sex, tobacco, alcohol usage, and baseline CD4 counts were not found as an independent risk factor for HIV disease progression (table not shown).

\section{Discussion}

From India, this is a first of its kind study that examined the likely effects of TLR7 (rs179008 and rs179009) polymorphisms on susceptibility to the acquisition of HIV-1 and disease progression. The genetic background of human populations can influence the susceptibility and outcome of infectious diseases. Reports suggested that the variations within the host's genome play a role in acquiring HIV infection and disease progression [19-24]. TLR gene variants and downstream signaling molecules could influence the ability of the affected individual to respond to TLR ligands resulting in altered susceptibility to or course of infectious disease [25-27]. TLR7 polymorphism plays a role in HIV disease progression and viral load [28].

In our study, the prevalence of TLR7 rs179008 AA, AT, and TT genotypes in healthy controls was $81.0 \%, 16.5 \%$, and $2.5 \%$. This finding was unmatched with that of the other studies carried out by $[12,13,29,14]$. The occurrence of TLR7 rs179008A/T allelic frequency was comparable with the study carried out by Valverde-Villegas et al., 2017, $[30,6,16]$ and dissimilar with the study reported by $[6,12,13,29]$. The occurrence of TLR7 rs179009 polymorphism was matched with studies published by Wang et al., [16] and unmatched with studies published by. We had observed a nonsignificant distribution of TLR7 rs179008 polymorphism between $\mathrm{HIV}$-infected individuals and healthy controls, although TLR7 rs179008AT genotype was much more prevalent in $\mathrm{HIV}$-infected individuals as 


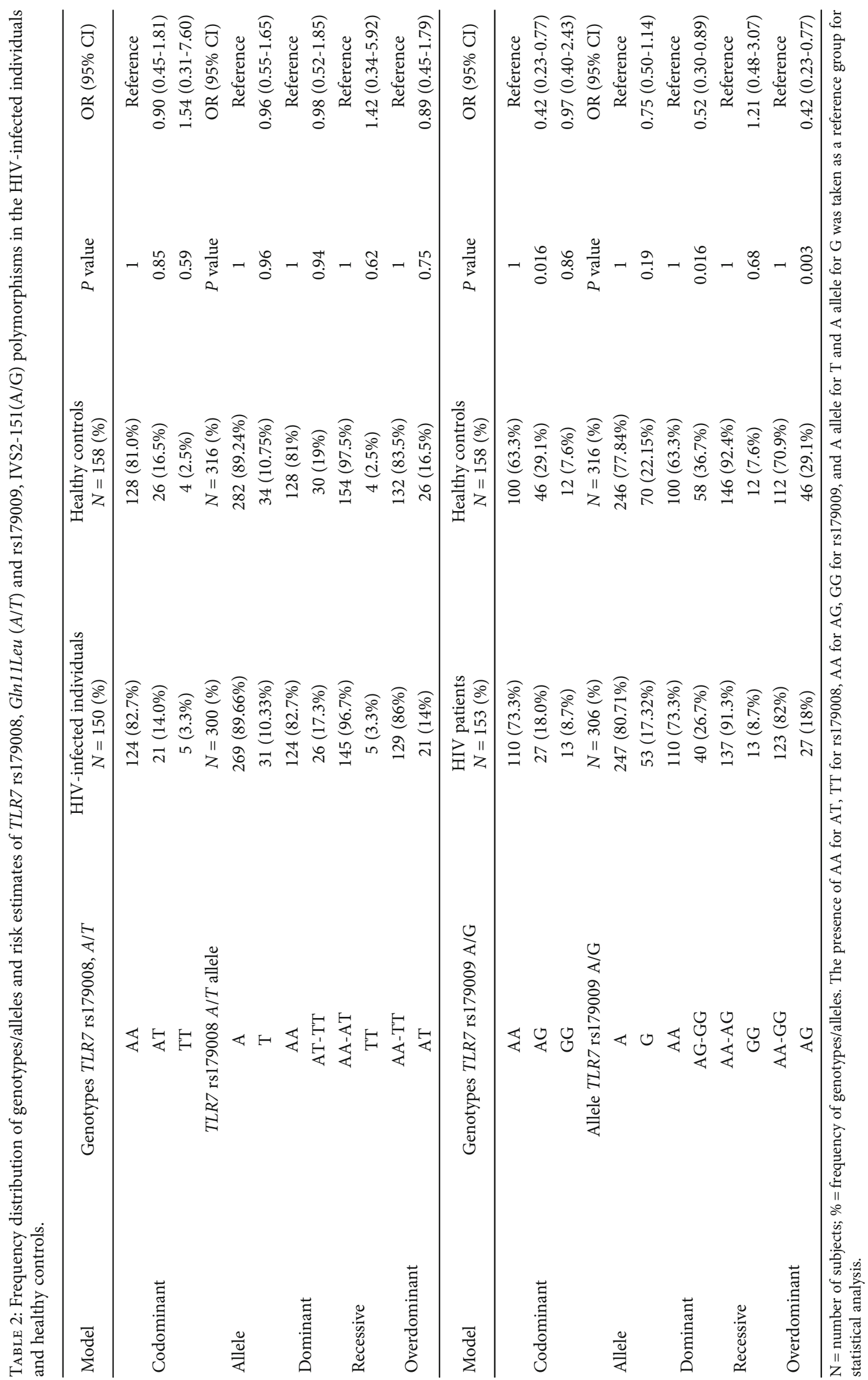


TABLE 3: Frequency distribution of haplotypes of TLR7 polymorphisms (rs179008, Gln11Leu (A/T) and rs179009, IVS2-151 (A/G)) in HIVinfected individuals and healthy controls.

\begin{tabular}{lcccc}
\hline $\begin{array}{l}\text { Haplotypes TLR7 } \\
\text { (rs179008 and rs179009) }\end{array}$ & $\begin{array}{c}\text { HIV-infected individuals } \\
N=300(\%)\end{array}$ & $\begin{array}{c}\text { Healthy controls } \\
N=316(\%)\end{array}$ & $P$ value & OR (95\% CI) \\
\hline AA & $75.33 \%$ & $72.44 \%$ & - & Reference \\
AG & $14.33 \%$ & $16.8 \%$ & 0.22 & $0.75(0.48-1.18)$ \\
TA & $7.00 \%$ & $5.41 \%$ & 0.43 & $1.35(0.64-2.84)$ \\
TG & $3.33 \%$ & $5.35 \%$ & 0.32 & $0.66(0.29-1.50)$ \\
\hline
\end{tabular}

$* N$ = number of chromosomes; $\%$ = haplotype frequency; age-adjusted odds ratios, and $95 \%$ CIs were derived from logistic regression models comparing the haplotype AA with other haplotypes.

compared to healthy controls $(3.3 \%$ vs. $2.5 \%, \mathrm{OR}=1.54)$. While as an association was seen between TLR7 rs179009AG genotype and acquisition of HIV-1 $(\mathrm{OR}=0.42, \quad P=0.016), \quad T L R 7 \mathrm{rs} 179008 \mathrm{~A} / \mathrm{T}$ polymorphism was associated with susceptibility to asthma [17], course of hepatitis C infection [12], HIV-1 acquisition, and disease progression [6]. TLR7 rs179008 polymorphism was not associated with patients of basal cell carcinoma (BCC) [12], melanoma cases $(P=0.245)$, and between single melanoma and MPM cases $(P=0.482)$ [14]. TLR7 IVS2-151G/A allele was associated with the protection of female patients of chronic hepatitis C $(P \leq 0.001$, $\mathrm{OR}=0.46)$ [15]. The finding of our study is supported by Wei et al., [15]. TLR7 IVS2-151GG genotype and IVS2$151 \mathrm{G}$ allele were associated with female HCV patients $(P=0.03$ and $\leq 0.001)$ [31]. TLR7 rs179008 (Gln11Leu) and rs179009 (IVS2-151A/G) polymorphisms were associated with the spontaneous clearance of HCV [13].

We also analyzed the haplotype to evaluate the synergistic role of two SNPs (rs179008 and rs179009) in the TLR7 gene cluster. The occurrence of TLR7 haplotype AG $(\mathrm{rs} 179008 * \mathrm{~A} / \mathrm{rs} 179009 * \mathrm{G})$ had increased in HIV-infected individuals as compared with healthy controls $(7.00 \%$ vs. $5.41 \%, \mathrm{OR}=1.35$ ).

We undertake a case-control study, CD4+ cell count used as a surrogate marker for HIV-1 infection. The timing for the acquisition of HIV-1 was unknown; hence, the effects may have had confounding consequences. Here, we analyzed the association of TLR7 (rs179008 and rs179009) polymorphisms with HIV disease stages to reveal the impact of TLR7 genotypes in the risk of HIV disease advancement. TLR7 rs179009AG genotype was associated with the early HIV disease stage individuals as compared with healthy controls $(\mathrm{OR}=0.11, P=0.001)$. The occurrence of the TLR7 rs179009 GG genotype was reduced in advanced HIV disease stage as compared with healthy controls $(1.6 \%$ vs. $7.6 \%$, $\mathrm{OR}=0.14, P=0.03)$. TLR7 $\mathrm{rs} 179008$ Gln11Leu polymorphism was associated with higher viral loads and accelerated progression to advanced immune suppression in HIV patients [6].

Most diseases are a consequence of a multifaceted interaction between an individual's genetic background and the environmental factors that individuals are exposed to. Gene-environment interaction describes the disease risk with individuals of different genotypes [32, 33]. Here, a case-only method is being adopted to evaluate geneenvironment interaction. It is considered a better method. For a case-control association study of environmental influences, cases must have matched controls in the population [34]. Therefore, we used a case-only study to evaluate the risk of HIV disease progression in alcohol and tobacco users. Individuals with HIV infection and excessive alcohol consumption had a negative impact on the CD4 cell count but not on combined antiretroviral therapy [35]. In a study, a decreased response to antiretroviral therapy was observed in women who were smoking and having HIV infection [36]. TLR7 rs179009AG genotype showed a risk for HIV disease progression among tobaccoconsuming HIV patients ( $26.1 \%$ vs. $17.2 \%, \mathrm{OR}=1.71)$. However, the risk could not reach significance. This suggested that HIV-infected individuals consuming tobacco with TLR7 rs179009AG genotypes are more prone to HIV disease progression.

The present study has certain limitations. (1) It can address the association. (2) It cannot establish causation. (3) We did not study the effect of other region polymorphisms of TLR7 gene on HIV infection and disease progression due to lack of funds. (4) We had not addressed the DNA sequences corresponding to the expression of mRNAs coding for variants and the actual proteins responsible in the cells due to budgetary constraints. (5) The control population was not exposed to HIV. (6) The data for viral load and other clinical manifestations were not recorded in our clinical research proforma (CRF).

In summary, overall, TLR7 rs179008 polymorphisms did not correlate with susceptibility to the acquisition of HIV and disease progression. TLR7 rs179009AG genotype could be protective for the acquisition of HIV-1. However, TLR7 rs179009A/G polymorphism could assist in disease progression among tobacco users. TLR7 rs179008 TT genotype in individuals with early HIV disease and rs179009 AG genotype in individuals with advanced HIV disease could protect the advancement of HIV disease. As TLR7 is an important player to trigger the IFN- $\gamma$ production, which exerts a direct antiviral effect through the inhibition of viral replication, it is also involved in the progression of HIV infection to AIDS. The present study should be validated with a bigger sample size in populations of other regions of India, since a limited study has been done concerning the influence of TLR7 rs179009A/G 


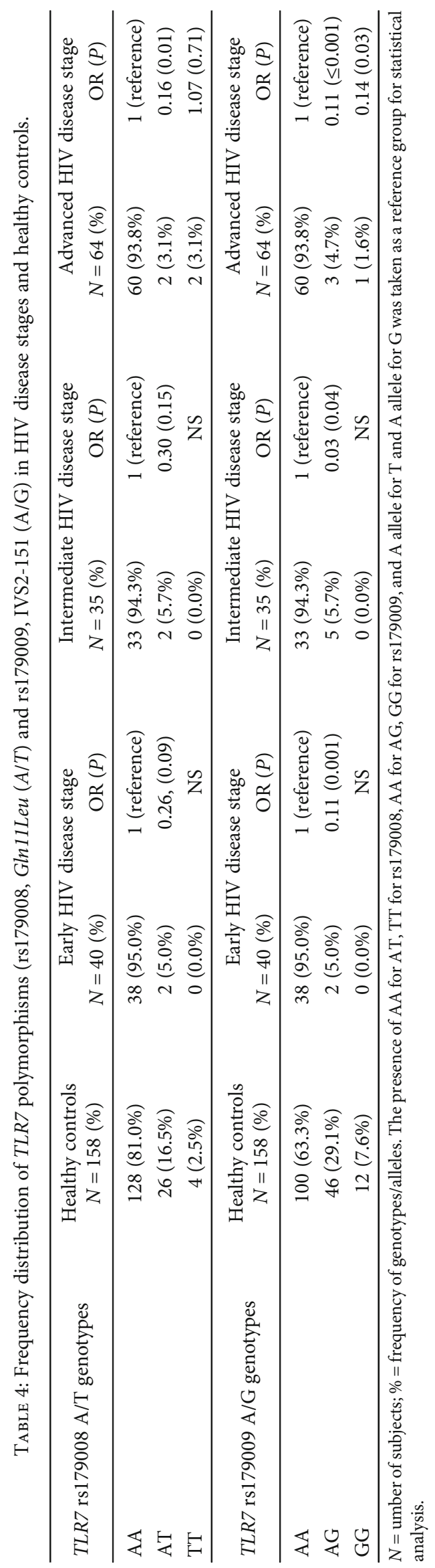


TABLE 5: Frequency distribution of TLR7 polymorphisms (rs179008, Gln11Leu (A/T) and rs179009, IVS2-151 (A/G)) in tobacco and alcohol using HIV-infected individuals and nonusers.

\begin{tabular}{|c|c|c|c|c|}
\hline TLR7 rs179008 A/T genotypes & $\begin{array}{c}\text { Tobacco users } \\
N=23(\%)\end{array}$ & $\begin{array}{l}\text { Tobacco nonusers } \\
\quad N=122(\%)\end{array}$ & $P$ value & OR 95\% CI \\
\hline $\mathrm{CC}$ & $19(82.6 \%)$ & $101(82.8 \%)$ & 1 & Reference \\
\hline CT & $3(13.0 \%)$ & $17(13.9 \%)$ & 0.81 & $0.94(0.20-3.89)$ \\
\hline TT & $1(4.3 \%)$ & $4(3.3 \%)$ & 0.70 & 1.33 (cornfield limits invalid) \\
\hline TLR7 rs179009 A/G genotypes & $\begin{array}{c}\text { Tobacco users } \\
N=23(\%)\end{array}$ & $\begin{array}{l}\text { Tobacco nonusers } \\
\qquad N=86(\%)\end{array}$ & $P$ value & OR 95\% CI \\
\hline AA & $15(65.2 \%)$ & $90(73.8 \%)$ & 1 & Reference \\
\hline AG & $6(26.1 \%)$ & $21(17.2 \%)$ & 0.47 & $1.71(0.52-5.49)$ \\
\hline GG & $2(8.7 \%)$ & $11(9.0 \%)$ & 0.75 & $1.09(0.0-6.09)$ \\
\hline TLR7 rs179008 A/T & $\begin{array}{l}\text { Alcohol users } \\
N=23(\%)\end{array}$ & $\begin{array}{l}\text { Alcohol nonusers } \\
\quad N=127(\%)\end{array}$ & $P$ value & OR 95\% CI \\
\hline AA & $20(87.0 \%)$ & $104(81.9 \%)$ & 1 & Reference \\
\hline AT & $3(13.0 \%)$ & $18(14.2 \%)$ & 0.91 & $0.87(0.18-3.55)$ \\
\hline TT & $0(0.0 \%)$ & $5(3.9 \%)$ & - & NS \\
\hline TLR7 rs179009 A/G & $\begin{array}{c}\text { Alcohol users } \\
N=18(\%)\end{array}$ & $\begin{array}{l}\text { Alcohol nonusers } \\
\quad N=90(\%)\end{array}$ & $P$ value & OR $(95 \% \mathrm{CI})$ \\
\hline AA & $18(78.3 \%)$ & $92(72.4 \%)$ & 1 & Reference \\
\hline$A G$ & $4(17.4 \%)$ & $23(18.1 \%)$ & 0.92 & $0.89(0.23-3.17)$ \\
\hline GG & $1(4.3 \%)$ & $12(9.4 \%)$ & 0.68 & $0.43(0.02-3.53)$ \\
\hline
\end{tabular}

$N=$ number of subjects; $\%$ = frequency of genotypes/alleles. The presence of AA for AT, TT for rs179008, AA for AG, GG for rs179009, and A allele for T and A allele for $\mathrm{G}$ was taken as a reference group for statistical analysis.

polymorphism on HIV infection and disease progression. Hence, to better understand the role of TLR7 rs179009A/G polymorphism in susceptibility to HIV infection and disease progression, further studies are needed.

\section{Data Availability}

Data can be available through request by email.

\section{Ethical Approval}

The study received ethical approval from the institutional ethics committee. ICF version 1.0 dated 18 April 2011.

\section{Conflicts of Interest}

The authors declare that they have no conflicts of interest.

\section{Authors' Contributions}

HariOm Singh did the overall supervision and writing of the manuscript. Dharmesh Samani performed the experiments and the analysis of data. Ranjana Choudhari critically reviewed the manuscript. Sumit Aggarwal performed the clinical input and critical review of the manuscript.

\section{Acknowledgments}

We gratefully acknowledge the clinician in charge, Dr. Seema Sahay, for the arrangement of the community staff for the recruitment of healthy controls. We are also thankful to Dr. Manisha Ghate and Dr. R.R Gangakhedkar, clinic in charge of model colony clinic and Gadikhana clinic for the recruitment of HIV patients. I would like to thank Asha Krishnaraj for helping in editing the manuscript. The study was supported by a research grant from the NARI-Indian Council of Medical Research (ICMR) India.

\section{References}

[1] R. D. Mackelprang, A. W. Bigham, C. Celum et al., "Toll-like receptor polymorphism associations with HIV-1 outcomes among sub-Saharan Africans," The Journal of Infectious Diseases, vol. 209, no. 10, pp. 1623-1627, 2014.

[2] M. Carrington and G. Alter, "Innate immune control of HIV," Cold Spring Harbor Perspectives in Medicine, vol. 2, no. 7, p. a007070, 2012.

[3] B. Beutler, Z. Jiang, P. Georgel et al., "Genetic analysis of host resistance: toll-like receptor signaling and immunity at large," Annual Review of Immunology, vol. 24, no. 1, pp. 353-389, 2006.

[4] K. Miyake, "Innate immune sensing of pathogens and danger signals by cell surface toll-like receptors," Seminars in Immunology, vol. 19, no. 1, pp. 3-10, 2007.

[5] H. Häcker, H. Mischak, T. Miethke et al., "CpG-DNA-specific activation of antigen-presenting cells requires stress kinase activity and is preceded by non-specific endocytosis and endosomal maturation," The EMBO Journal, vol. 17, no. 21, pp. 6230-6240, 1998.

[6] D. Y. Oh, K. Baumann, O. Hamouda et al., "A frequent functional toll-like receptor 7 polymorphism is associated with 
accelerated HIV-1 disease progression," AIDS, vol. 23, no. 3, pp. 297-307, 2009.

[7] K. Takeda, T. Kaisho, and S. Akira, "Toll-like receptors," Annual Review of Immunology, vol. 21, no. 1, pp. 335-376, 2003.

[8] E. Seki and D. A. Brenner, "Toll-like receptors and adaptor molecules in liver disease: update," Hepatology, vol. 48, no. 1, pp. 322-335, 2008.

[9] P. L. Cheng, H. L. Eng, M. H. Chou, H. L. You, and T. M. Lin, "Genetic polymorphisms of viral infection-associated toll-like receptors in Chinese population," Translational Research, vol. 150, no. 5, pp. 311-318, 2007.

[10] E. A. Said, F. Al-Yafei, F. Zadjali et al., "Association of singlenucleotide polymorphisms in TLR7 (Gln11Leu) and TLR9 $(1635 \mathrm{~A} / \mathrm{G})$ with a higher CD4T cell count during HIV infection," Immunology Letters, vol. 160, no. 1, pp. 58-64, 2014.

[11] E. Schott, H. Witt, K. Neumann et al., "Association of TLR7 single nucleotide polymorphisms with chronic HCVinfection and response to interferon-a-based therapy," Journal of Viral Hepatitis, vol. 15, no. 1, pp. 71-78, 2008.

[12] I. Russo, C. Cona, A. Saponeri, F. Bassetto, V. Baldo, and M. Alaibac, "Association between toll-like receptor 7 Gln11Leu single-nucleotide polymorphism and basal cell carcinoma," Biomed Rep., vol. 4, no. 4, pp. 459-462, 2016.

[13] F.-Z. Fakhir, M. Lkhider, W. Badre et al., "Genetic variations in toll-like receptors 7 and 8 modulate natural hepatitis $\mathrm{C}$ outcomes and liver disease progression," Liver International, vol. 38, no. 3, pp. 432-442, 2018.

[14] L. I. S. A. Elefanti, G. Sacco, and C. Stagni, “TLR7 Gln11Leu single nucleotide polymorphism and susceptibility to cutaneous melanoma," Oncology Letters, vol. 12, no. 1, pp. 275-280, 2016.

[15] X. S. Wei, C. D. Wei, Y. Q. Tong, C. L. Zhu, and P. A. Zhang, "Single nucleotide polymorphisms of toll-like receptor 7 and toll-like receptor 9 in hepatitis $C$ virus infection patients from central China," Yonsei Medical Journal, vol. 55, no. 2, pp. 428434, 2014.

[16] C. H. Wang, H. L. Eng, K. H. Lin et al., "TLR7 and TLR8 gene variations and susceptibility to hepatitis C virus infection," PLoS One, vol. 6, no. 10, article e26235, 2011.

[17] S. Møller-Larsen, M. Nyegaard, A. Haagerup, J. Vestbo, T. A. Kruse, and A. D. Børglum, "Association analysis identifies TLR7 and TLR8 as novel risk genes in asthma and related disorders," Thorax, vol. 63, no. 12, pp. 1064-1069, 2008.

[18] S. Arslan, A. Engin, N. Özbilüm, and M. Bakır, "Toll-like receptor 7 Gln11Leu, c. $4-151 \mathrm{~A} / \mathrm{G}$, and $+1817 \mathrm{G} / \mathrm{T}$ polymorphisms in Crimean Congo hemorrhagic fever," Journal of Medical Virology, vol. 87, no. 7, pp. 1090-1095, 2015.

[19] M. Dean, M. Carrington, C. Winkler et al., "Genetic Restriction of HIV-1 Infection and Progression to AIDS by a Deletion Allele of the CKR5 Structural Gene," Science, vol. 273, no. 5283, pp. 1856-1862, 1996.

[20] C. Winkler, W. Modi, M. W. Smith et al., "Genetic restriction of AIDS pathogenesis by an SDF-1 chemokine gene variant. ALIVE Study, Hemophilia Growth and Development Study (HGDS), Multicenter AIDS Cohort Study (MACS), Multicenter Hemophilia Cohort Study (MHCS), San Francisco City Cohort (SFCC)," Science, vol. 279, no. 5349, pp. 389-393, 1998.

[21] M. P. Martin, X. Gao, J. H. Lee et al., "Epistatic interaction between KIR3DS1 and HLA-B delays the progression to AIDS," Nature Genetics, vol. 31, no. 4, pp. 429-434, 2002.
[22] E. Trachtenberg, B. Korber, C. Sollars et al., "Advantage of rare HLA supertype in HIV disease progression," Nature Medicine, vol. 9, no. 7, pp. 928-935, 2003.

[23] E. C. Speelmon, D. Livingston-Rosanoff, S. S. Li et al., "Genetic association of the antiviral restriction factor TRIM5alpha with human immunodeficiency virus type 1 infection," Journal of Virology, vol. 80, no. 5, pp. 2463-2471, 2006.

[24] M. Altfeld, E. T. Kalife, Y. Qi et al., "HLA alleles associated with delayed progression to aids contribute strongly to the initial CD8+ T cell response against HIV-1," PLoS Medicine, vol. 3, no. 10, article e403, 2006.

[25] C. C. Khor, S. J. Chapman, F. O. Vannberg et al., "A Mal functional variant is associated with protection against invasive pneumococcal disease, bacteremia, malaria and tuberculosis," Nature Genetics, vol. 39, no. 4, pp. 523-528, 2007.

[26] F. P. Mockenhaupt, J. P. Cramer, L. Hamann et al., "Toll-like receptor (TLR) polymorphisms in African children: common TLR-4 variants predispose to severe malaria," Proceedings of the National Academy of Sciences, vol. 103, no. 1, pp. 177-182, 2006.

[27] N. W. J. Schroder and R. R. Schumann, "Single nucleotide polymorphisms of toll-like receptors and susceptibility to infectious disease," The Lancet Infectious Diseases, vol. 5, no. 3, pp. 156-164, 2005.

[28] L. Stevceva, "Toll-like receptor agonists as adjuvants for HIV vaccines," Current Medicinal Chemistry, vol. 18, no. 33, pp. 5079-5082, 2011.

[29] S. I. Buschow, P. J. Biesta, Z. M. A. Groothuismink et al., "TLR7 polymorphism, sex and chronic HBV infection influence plasmacytoid DC maturation by TLR7 ligands," Antiviral Research, vol. 157, pp. 27-37, 2018.

[30] J. M. Valverde-Villegas, B. P. Dos Santos, R. M. de Medeiros et al., "Endosomal toll-like receptor gene polymorphisms and susceptibility to HIV and HCV co-Infection-differential influence in individuals with distinct ethnic background," Human Immunology, vol. 78, no. 2, pp. 221-226, 2017.

[31] M. Embaby, O. Shaker, G. Abd El Aziz, A. Rashad, and A. Yousri, "Toll like receptor $7 \& 8$ gene variations and sustained virological response in hepatitis $C$ virus patients treated with interferon," J Adv Pharm Edu Res, vol. 8, no. 3, pp. 9-15, 2018.

[32] H. E. Gendelman, R. M. Friedman, S. Joe et al., "A selective defect of interferon alpha production in human immunodeficiency virus-infected monocytes," The Journal of Experimental Medicine, vol. 172, no. 5, pp. 1433-1442, 1990.

[33] Y. Deng, B. Newman, M. P. Dunne, P. A. Silburn, and G. D. Mellick, "Case-only study of interactions between genetic polymorphisms of GSTM1, P1, T1 and Z1 and smoking in Parkinson's disease," Neuroscience Letters, vol. 366, no. 3, pp. 326-331, 2004.

[34] T. Y. Chen, Y. C. Li, Y. F. Liu et al., "Role of MMP14 gene polymorphisms in susceptibility and pathological development to hepatocellular carcinoma," Annals of Surgical Oncology, vol. 18, no. 8, pp. 2348-2356, 2011.

[35] J. H. Samet, S. J. Phillips, N. J. Horton, E. T. Traphagen, and K. A. Freedberg, "Detecting alcohol problems in HIV-infected patients: use of the CAGE questionnaire," AIDS Research and Human Retroviruses, vol. 20, no. 2, pp. 151-155, 2004.

[36] J. G. Feldman, H. Minkoff, M. F. Schneider et al., "Association of cigarette smoking with HIV prognosis among women in the HAART era: a report from the women's interagency HIV study," American Journal of Public Health, vol. 96, no. 6, pp. 1060-1065, 2006. 